\title{
Panorámica sobre los avances y retos de la inclusión electoral en América Latina
}

Carlos Marino Navarro Fierro*

https://doi.org/10.35242/RDE $2020 \quad 30 \quad 3$

Nota del Consejo Editorial

Recepción: 23 de mayo de 2020.

Revisión, corrección y aprobación: 3 de junio de 2020.

Resumen: Analiza los cambios implementados en la normativa electoral en 18 países de América Latina que promueven la inclusión al ejercicio de los derechos políticos y electorales no solo de colectivos sociales como las mujeres, pueblos originarios, minorías étnicas y personas con discapacidades diferentes, sino que, también, la incorporación de otros grupos con otras limitaciones como lo son las personas recluidas en centros penitenciarios o la comunidad LGTBI. A pesar de las reformas realizadas, aún se mantienen barreras legales como, por ejemplo, para personas con discapacidades psicosociales, privados de libertad sin sentencia, personas habitantes de la calle, o el desamparo a la juventud que cuentan con bajos niveles de presencia en instancias de representación política.

Palabras clave: Derechos políticos / Derecho al sufragio / Representación política / Igualdad de oportunidades / Equiparación de condiciones / Accesibilidad / Voto preferente / Equidad de género / Voto en el extranjero / Derechos de las minorías / Fuerzas de seguridad / Privados de libertad / Insania / Grupos étnicos / Identidad de género.

Abstract: The article analyzes the changes implemented on the electoral norm in 18 Latin American countries. The changes foster the inclusion of exercising political rights not only of social collectives such as women, indigenous peoples, ethnic minorities and people with different disabilities but also the incorporation of other groups with constraints such as inmates from prisons or the LGBTI community. In spite of the reforms made, there are still legal barriers such as, for example, people with psychosocial disabilities, inmates without a conviction, homeless people or the abandonment of the youth with very low levels of presence in political representation.

Key Words: Political rights / Right to suffrage / Political representation / Equality of opportunities / Parity of conditions / Accessibility / Preferred vote / Gender equity / Voting abroad / Minority rights / Security forces / Inmates / Insanity / Ethnic groups / Gender identity.

\footnotetext{
Mexicano, relacionista público, correo carlos.navarro@ine.mx. Egresado de la licenciatura en Relaciones Internacionales y de la maestría en Estudios Latinoamericanos por la Facultad de Ciencias Políticas y Sociales de la Universidad Nacional Autónoma de México (UNAM). Director de Estudios y Proyectos en el área internacional del Instituto Nacional Electoral (INE).
} 


\section{DERECHO ELECTORAL}

\section{DigRESIÓN INTRODUCTORIA}

Hacia finales de enero de este 2020, cuando se concretó la invitación que gentilmente me formularon del Tribunal Supremo de Elecciones de Costa Rica para colaborar en la edición conmemorativa del XV aniversario de la publicación de esta prestigiosa revista, empezaban ya a trascender y provocar algunas inquietudes las notas informativas sobre el surgimiento de una nueva enfermedad respiratoria causada por un virus que podía ser letal. Todavía se le llamaba coronavirus, pero su foco de irradiación aún se ubicaba en tierras muy distantes.

De alguna forma, los procesos atinentes al bosquejo de las ideas iniciales sobre el contenido de esta colaboración y al de la rápida evolución y dispersión de esa enfermedad viral, que ya para marzo fue denunciada por la OMS como una pandemia y que pronto empezó a causar dramáticos estragos en varios planos de la vida en sociedad a escala global, se fueron dando de manera simultánea. Me parece que justo al momento de llegar al tramo final de la preparación de este artículo hay razones suficientes, espero que no enteramente subjetivas, para dejar aquí un testimonio, eso sí personal, sobre algunos puntos de convergencia entre ambos procesos. Para ser claros, el de la concepción y concreción de esta obra en su conjunto y el de los efectos provocados por la pandemia dentro de un espacio natural de reflexión y acción: el de los valores, las normas, las instituciones y los procedimientos democráticos.

La primera razón es precisamente esa. Dejar testimonio de que esta obra se fraguó en tiempos de crisis asociados al covid-19, con las complejidades de reflexión y trabajo editorial que toda crisis comporta, sobre todo si impone inusuales medidas de confinamiento y aislamiento social, al menos para quien puede darse esos lujos. El que a uno le gusten o los prefiera, ya es otra cosa.

La segunda reside en que, como ya se ha empezado a debatir y documentar con cierta profusión y profundidad, los cuadros de crisis que está provocando la pandemia del covid-19, en varios planos de la vida social y económica, se registran en momentos en que ya eran perceptibles algunos signos de estancamiento o regresión democrática en varias regiones y países alrededor del mundo. Léase en clave de pulsiones autoritarias, rebrotes nacionalistas o xenofóbicos, nuevos populismos o 


\section{DERECHO EIECTORAL}

quiebres democráticos, las mediciones de densidad, calidad o simple pulso ya mostraban signos inquietantes de tiempo atrás ${ }^{1}$. En este sentido, un nuevo vector de inquietud radica en que, al parecer, los Gobiernos de algunos países donde ya eran perceptibles ese tipo de signos han encontrado en la necesidad de adoptar medidas excepcionales para hacer frente a la pandemia una coartada perfecta para justificar o reforzar el uso de poderes discrecionales, incluido el de suprimir derechos y libertades fundamentales como el de la libertad de expresión, sin contrapeso institucional ni garantía de devolución alguna.

La tercera tiene que ver con los debates que se han suscitado y las decisiones que se han tomado respecto a la celebración o postergación de elecciones o consultas ciudadanas programadas en el marco de las medidas de emergencia adoptadas para hacer frente a la pandemia (medidas muy heterogéneas, por cierto, lo que no deja de ser indicativo de carencias de liderazgo $o$ al menos de obligada coordinación internacional para hacer frente a una dramática crisis de alcance global). De acuerdo con los registros disponibles, la mayoría de los países que tenían programadas elecciones o consultas populares durante el segundo trimestre de 2020 han optado por aplazarlas, pero hay incertidumbre sobre las condiciones bajo las que se podrán llevar a cabo y respecto de las exigencias, cargas y costos adicionales que impondrá su verificación en el futuro próximo. Otros han tomado la decisión de celebrar sus comicios en medio de la pandemia y, salvo el excepcional y ya célebre caso de Corea del Sur, sus experiencias distan de ser edificantes 0 encomiables $y$ han recibido fuertes cuestionamientos.

Ninguna decisión en este sentido y de este calibre ha sido ni será sencilla. Ha hecho su aparición de manera fulgurante en el escenario políticoelectoral un actor inédito que obliga a pensar en la organización y la competencia electorales, al menos ahora y en un futuro previsible, también

\footnotetext{
${ }^{1}$ El concepto de democracia, sobre todo en su acepción contemporánea y, en especial, referida a los regímenes políticos que reivindican su adscripción a ella nunca ha estado exenta de controversias. En todo caso, los cuestionamientos recientes se refieren a las nociones que se propagan y a los regímenes que se configuran en buena parte del mundo occidental después del colapso del bloque soviético. En este sentido, no deja de ser ilustrativo que la edición conmemorativa del 25 aniversario de la revista especializada en el tema Journal of Democracy, publicada en 2015, se dedicara precisamente a analizar, desde distintas ópticas, interrogantes a propósito del declive de la democracia. Ahí se reflejan o de ahí se retoman muchas ideas y conceptos que hoy han adquirido carta de naturalización. Más en específico, sobre el impacto e implicaciones de la pandemia del coronavirus en la esfera político-electoral, ya era notable durante el periodo marzo-mayo de 2020 la publicación de reportes, artículos y opiniones especializadas, algunos de los cuales se podían consultar (al menos temporalmente), en el portal de la Red de Conocimientos Electorales ACE (www.ace.org), así como en los de IDEA Internacional (www.idea.int) y de IFES (www.ifes.org).
} 


\section{DERECHO ELECTORAL}

en términos de imperativos y exigencias de salud pública. De manera inopinada, la pandemia del covid-19, no sólo ha puesto en juego, sino también creado tensiones y dilemas entre el derecho a la salud, a la vida si se piensa en situaciones extremas, y principios y valores consustanciales al orden democrático, incluyendo el ejercicio de los derechos políticoelectorales y la renovación periódica de gobiernos y autoridades electas popularmente, por citar los más evidentes. Las interrogantes y las incertidumbres son muchas, los dilemas y retos, por consiguiente, también. Para hacer frente a los nuevos desafíos se tienen que considerar y se están explorando ya tanto alternativas disponibles como opciones innovadoras.

Uno de los muchos dilemas que se está ponderando es el relativo a las alternativas que se pueden utilizar para la emisión del voto en un contexto de obligadas medidas de higiene y distanciamiento social que complican la modalidad presencial y masiva que predomina en la región. El debate y las propuestas sobre este asunto en particular se enlazan, en alguna medida, con uno de los puntos que se abordan como parte de la temática central de este texto. En efecto, tanto para la emisión del voto en el extranjero como para facilitar el sufragio dentro de su territorio de otros grupos o segmentos del electorado que, por diversas razones, no pueden comparecer personalmente ante las mesas el día de la jornada comicial; varios países ya han operado modalidades alternativas de votación que, introducidas o expandidas con la debida planeación y cuidado, pueden ayudar a sortear algunas de las exigencias impuestas por la pandemia. Una disculpa por la larga digresión y ahora sí pasamos a ocuparnos del tema central originalmente previsto que, por razones de espacio, se tratará de manera sintetizada, anticipando que se expone con más detalle en un estudio comparado que se espera concluir y publicar en breve.

\section{SOBRE LA INCLUSIÓN ELECTORAL}

El objetivo de este artículo es ofrecer una visión panorámica de algunos de los dispositivos legales o programas institucionales que se han instrumentado en 18 países de la región (los 16 hispanoparlantes a nivel continental más República Dominicana y Brasil), en los últimos tiempos para promover o facilitar el ejercicio de los derechos político-electorales fundamentales de algunos grupos o colectivos sociales que, por diversas razones no han tenido o no suelen tener las garantías, oportunidades o facilidades necesarias para su pleno o debido ejercicio. Es decir, dispositivos 


\section{DERECHO ELECTORAL}

y mecanismos que buscan fortalecer los regímenes electorales en un sentido y con un carácter incluyente.

El concepto de inclusión se emplea en un sentido más amplio al que convencionalmente suele predominar en el ámbito político-electoral. No sólo trata de abarcar a algunos de los grupos o colectivos sociales que suelen exigir o frente a los cuales se suelen reivindicar con mayor asiduidad acciones afirmativas, como lo pueden ser las mujeres, los pueblos originarios, las minorías étnicas, las personas con capacidades diferentes o las que residen en el extranjero. También, se ha buscado incorporar a otros grupos o colectivos sobre cuyos integrantes pesan otros condicionamientos o limitantes que afectan el reconocimiento o el ejercicio de sus derechos políticos y que hasta hace relativamente poco no eran objeto de especial atención no sólo en el plano jurídico-institucional o en el administrativo y procedimental, sino incluso en el del debate público y hasta en el trabajo académico. El repertorio va desde las personas recluidas en centros penitenciarios, hasta el de las pertenecientes a la comunidad LGTBI, en especial, las transgénero, pasando por aquellas que a lo largo el proceso electoral o, al menos, durante la jornada electoral enfrentan circunstancias que les dificultan o de plano les impiden comparecer personalmente a la mesa de votación que les corresponde para ejercer su derecho al voto, como las que se encuentran recluidas en centros de salud o asistencia social o simplemente se encuentran desempeñando funciones oficiales fuera de su jurisdicción electoral.

Como es fácil advertir, el elenco de grupos y colectivos sociales en los que se pueden concentrar esfuerzos y medidas de inclusión es muy diverso y, además, sus necesidades o exigencias pueden ser distintas y demandar dispositivos o acciones diferenciadas. Por consiguiente, los dispositivos o políticas de inclusión pueden apuntar al logro de distintos objetivos específicos, muchos de los cuales se relacionan con la situación que se pretende remediar o las exigencias que se buscan atender de un determinado grupo o colectivo social.

Para cumplir con su cometido y conciliar estos elementos, la exposición central comprende tres apartados. En el primero, se presenta una panorámica sobre la situación que impera en la región a propósito de grupos sobre los que gravitan restricciones de carácter legal, es decir, expresamente previstas en el marco jurídico, centrando la atención en dos de ellos: el de las personas que pertenecen a fuerzas de seguridad, sobre todo las militares, y el de las recluidas en centros penitenciarios. En el 


\section{DERECHO EIECTORAL}

segundo, la atención se desplaza hacia grupos o colectivos sobre los que, para efectos del ejercicio de sus derechos, en especial el del voto activo, no pesan prohibiciones o restricciones expresas de carácter legal, sino más bien obstáculos o limitaciones de índole sociocultural o simplemente burocráticos-administrativos, y algunos de los dispositivos que se han adoptado para remontarlos. En la tercera, el énfasis se coloca en los dispositivos orientados a responder a expectativas o exigencias de grupos que reivindican demandas que se insertan ya más bien en el plano de la representación política.

\subsection{INCLUSIÓN Y BARRERAS LEGALES}

De acuerdo con la teoría, los principios y la jurisprudencia internacionalmente reconocidas sobre la garantía y protección de los derechos humanos, y en especial al amparo de lo dispuesto por el Pacto Internacional de Derechos Civiles y Políticos suscrito en 1966, el grueso de la población debe tener, al alcanzar la edad necesaria, plenas garantías para el disfrute y ejercicio de sus derechos político-electorales. Empero, la misma doctrina e instrumentos jurídicos reconocen y admiten la posibilidad de que, en ejercicio de su potestad soberana, los Estados pauten reglas (ergo, impongan restricciones, límites o condiciones generales, razonables y no discriminatorias), para la asunción y ejercicio de esos derechos. Y muchos Estados alrededor del mundo, aún algunos que reivindican credenciales democráticas o reafirman su adhesión a los principios esenciales del Estado de derecho, han impuesto algunas restricciones de esa índole. Hay, ya de entrada, elementos para debatir, con mayor o menor soporte y echando mano de argumentos opuestos, la imposición de barreras legales para la titularidad y ejercicio de los derechos políticos.

En perspectiva comparada tenemos que, al margen de particularidades propias de algunas regiones y países, entre las personas sobre las que con mayor frecuencia suelen pesar disposiciones, usualmente de rango constitucional, que prescriben la pérdida o la suspensión de ciertos derechos, entre ellos notoriamente los político-electorales, figuran las que forman parte de las fuerzas de seguridad del Estado, sobre todo las de carácter militar o las que se encuentran recluidas en centros penitenciarios. 


\section{DERECHO ELECTORAL}

\subsection{LAS FUERZAS DE SEGURIDAD}

Por una notoria propensión histórica a intervenir o interferir drásticamente en la vida político-institucional, no resulta del todo incomprensible que, más allá de los reparos y restricciones que se les tiende a imponer por su propia naturaleza y función social en diversas latitudes, en algunos países de América Latina la temática relacionada con los derechos y obligaciones políticas de los integrantes de las fuerzas armadas en lo particular, y con las del conjunto de las fuerzas de seguridad pública en su conjunto (cabe recordar que Costa Rica y Panamá no tienen fuerzas armadas), tienda aún hoy en día a dividir opiniones y a ser motivo de controversias ${ }^{2}$. En todo caso, se trata de un asunto abierto a debate, sobre el que la dinámica doctrinaria, jurisprudencial y regulatoria apunta a procesos sistemáticos de revisión y posible ajuste.

La panorámica de la región muestra que, de los 18 países examinados en este artículo, una abrumadora mayoría (14 que representan casi el $80 \%$, excepto Colombia, Guatemala, Honduras y República Dominicana) reconoce el derecho al voto para quienes integran las fuerzas de seguridad pública, incluyendo las armadas ${ }^{3}$. Si bien esta habilitación suele tener carácter general, es decir, se explicita o entiende de manera tácita como aplicable a todas las corporaciones de seguridad en sus diversos grados, niveles o modalidades, hay algunos casos como los de Brasil y Paraguay en los que se excluye a los conscriptos que cumplen el servicio militar obligatorio o a quienes estén matriculados en academias militares o policiales.

En los cuatro países de la región en que se veda el derecho al sufragio de las y los integrantes de las fuerzas armadas, la prohibición se extiende a las corporaciones civiles de seguridad pública como las guardias, policías o gendarmerías nacionales. Es importante hacer notar que en los cuatro países, pero sobre todo en Colombia, la persistencia de esa prohibición ha sido motivo tanto de debate público como de diversas propuestas e iniciativas para suprimirla.

\footnotetext{
${ }^{2}$ En perspectiva internacional comparada, la práctica más extendida es la de reconocerles el derecho al voto a las y los integrantes de las fuerzas de seguridad y, en menor medida y con algunas restricciones como la de no estar en servicio activo, la de permitirles contender por cargos de elección popular. A propósito de sus derechos, es útil consultar las recomendaciones adoptadas por el Comité de Ministros del Consejo de Europa en 2010 y en 2014, https://www.casede.org/index.php/biblioteca-casede-2-0/derechos-humanos/279manual-sobre-derechos-humanos-y-libertades-fundamentales-del-personal-de-las-fuerzas-armadas/file

3 Todos los registros y datos que se consignan en el artículo respecto a la situación de los 18 países de América Latina derivan primordialmente de consultas a su legislación o la información contenida en los portales de la respectiva autoridad electoral. Las tablas son de elaboración propia para este artículo.
} 


\section{DERECHO ELECTORAL}

Por otra parte, es claro que existe una solución natural de continuidad entre los derechos y libertades que tiene una persona para participar en actividades de carácter político-partidista, en particular las de proselitismo o propaganda con fines electorales, y su posibilidad de postularse y contender por un cargo de elección popular. En el caso de quienes integran las fuerzas armadas y, más en general de cualquier otra corporación de seguridad pública, no sólo gravitan en los debates y definiciones correspondientes a las consideraciones relacionadas con la naturaleza y atributos de sus funciones (entre ellos los de lealtad y disciplina institucional y su carácter no deliberante), sino además las que derivan, en general, de su carácter de oficiales y/o servidoras y servidores públicos.

De ahí que no resulte del todo sorprendente que en todos los países de la región, incluyendo los cuatro en que se les impide el voto activo, se les impongan prohibiciones o restricciones tanto para participar en actividades políticas y partidistas como para postularse a cargos de elección. Esas prohibiciones o restricciones son aplicables de manera sustancial, pero no exclusiva, mientras su pertenencia a esas corporaciones tiene un carácter activo, es decir, se encuentran en ejercicio efectivo de sus funciones.

La evidencia legal disponible indica simple y llanamente que, en casi todos los países, si una o un efectivo de las fuerzas de seguridad, en especial de las armadas, desea contender por un cargo de elección no sólo debe separarse o haberse separado del cargo con cierta antelación a la jornada comicial (las exigencias van desde unos cuantos meses hasta varios años), sino que, además, el trámite implica su pase a situación de retiro o baja de la corporación. Es decir, a diferencia de lo que ocurre con el grueso de las personas que ocupan otro tipo de cargos públicos a quienes también se les exige renunciar o solicitar licencia como requisito para contender por un cargo de elección; en el caso de las y los integrantes de las fuerzas de seguridad pública, la búsqueda de una candidatura no implica, en la mayoría de los casos, una baja de carácter temporal de un servicio que suele ser de carrera, sino la imposibilidad de reingresar a él, es decir, su separación definitiva.

\subsection{LAS PERSONAS RECLUIDAS EN CENTROS PENITENCIARIOS}

La imposición de una sanción penal que comporte la pérdida de la libertad constituye una de las situaciones prototípicas en las que el derecho, los principios y los instrumentos jurídicos internacionales aplicables admiten la 


\section{DERECHO EIECTORAL}

posibilidad de que un Estado prescriba la suspensión o cancelación de la titularidad o ejercicio de los derechos políticos de una persona. Y lo usual es que lo haga. No obstante, se trata de un asunto sobre el que los desarrollos recientes indican que, si las hubo, hoy se han diluido las bases de consenso tanto sobre la procedencia y pertinencia de esta exclusión desde un punto de vista filosófico y doctrinal como, de ser el caso, los alcances de su aplicación ${ }^{4}$. En efecto, en clave comparada se vislumbra una clara tendencia a cuestionar, revisar y revertir o matizar este tipo de sanción, al punto de que en América Latina, suman ya nueve los países en que el encarcelamiento no implica, al menos, la pérdida del derecho al sufragio activo.

Es claro que la condición de reclusión en un centro penitenciario puede comportar estatus judiciales e implicaciones jurídicas susceptibles de variar de un contexto a otro. Sobre esta base, resulta particularmente pertinente considerar la distinción que se puede establecer entre las personas "detenidas", es decir, aquellas que están recluidas de manera preventiva y/o sujetas a un proceso judicial en curso, de aquellas otras efectivamente "presas" en el sentido de que su privación de la libertad es resultado de una sentencia judicial condenatoria. Sobre esta base, es relativamente sencillo discernir una diferencia significativa entre las personas recluidas legalmente en centros penitenciarios para fijar una posición a propósito de sus derechos político-electorales y las implicaciones prácticas que ello puede comportar. No da lo mismo suspender o privar de esos derechos a una persona sólo detenida que a una sentenciada. Esta diferencia obliga a que el marco jurídico aplicable precise si esa suspensión o privación se produce como resultado de la simple reclusión, o bien, si para ello debe mediar sentencia judicial condenatoria.

Sucede entonces que la privación de la libertad sin que medie sentencia se traduce, en la práctica, en una conculcación indebida de los derechos políticos, situación agravada por el hecho de que, con frecuencia, los procesos judiciales en muchos países de la región son muy lentos y la vulneración de esos derechos prolongada. Así, pueden mediar largos periodos entre el momento de la reclusión y la consecuente sentencia

\footnotetext{
${ }^{4}$ Los derechos políticos de las personas encarceladas son objeto tanto de un amplio debate como de una notable publicación de opiniones y de literatura especializada, sobre todo en inglés. Al respecto, destacan las publicaciones del Journal of Ethics and Global Politics que se pueden consultar en el siguiente portal (https://www.tandfonline.com/toc/zegp20/current, en especial "Voting from prison: against the democratic case for disenfranchisement", de Pablo Marshall y "Voters should not be in prisoni The rights of prisoners in democracy", de Peter Ramsay.
} 


\section{DERECHO EIECTORAL}

judicial. En todo caso es conveniente subrayar que, por razones comprensibles, derivadas sobre todo de su situación de segregación social, es notorio que tanto los debates como las soluciones planteadas a cuestiones relacionadas con la titularidad y el ejercicio de los derechos políticos de las personas recluidas en centros penitenciarios suelen concentrarse en su capacidad electoral activa.

Con todo, es notable el hecho de que nueve países de la región cuenten con disposiciones y dispositivos legales que reconocen y posibilitan la emisión del voto por parte de las personas encarceladas. El registro es aún notable si se toma en cuenta que todavía a mediados de la década de 1990, en pleno auge de los procesos de arraigo y fortalecimiento democrático, no había un solo país en la región con registro positivo. Claramente está en marcha una tendencia progresiva que tiene dos referentes importantes entre los Estados soberanos de la región, Costa Rica y Colombia, pues en rigor el país pionero en la región en la introducción del denominado voto penitenciario fue Puerto Rico en 1977.

Gradualmente se han sumado al elenco Argentina, Bolivia, Brasil, Ecuador, Panamá, República Dominicana y Venezuela. Conviene destacar que, en rigor y a juzgar al menos por las disposiciones constitucionales vigentes, en ninguno de los nueve países con registro negativo está expresamente indicado que la simple detención en centros penitenciarios sea causal de pérdida o suspensión de los derechos políticos. Consecuentemente, al menos en el caso de los detenidos no sentenciados se está en una conculcación indebida de sus derechos políticos.

De ahí que no resulte sorprendente que en casi todos ellos no sólo se hayan manifestado exigencias orientadas a subsanar esa omisión, especialmente en pro de reconocer y facilitar el voto a las personas detenidas, sino que incluso se hayan tramitado, sin éxito aún, iniciativas legislativas o incluso producido sentencias judiciales en esa dirección. En Chile, por ejemplo, está pendiente de cumplimiento una sentencia emitida por la Suprema Corte de Justicia en 2017 que declara ilegal la privación del derecho al voto para las personas que no han sido sentenciadas o que lo han sido por delitos menores y ordena que se tomen las medidas necesarias para remediar esa situación. En el caso de México, el Tribunal Electoral del Poder Judicial de la Federación emitió en 2019 una sentencia en el mismo sentido, que 


\section{DERECHO EIECTORAL}

previsiblemente se instrumentará por vez primera en las elecciones de $2024^{5}$.

En relación a los nueve países con registro positivo, se puede destacar que en siete de ellos, las disposiciones y dispositivos para la emisión del voto se limitan a las personas detenidas, es decir, sin sentencia. En esta situación encontramos a Argentina, Bolivia, Brasil, Colombia, Ecuador, República Dominicana y Venezuela. Por su parte, tanto en Costa Rica como en Panamá, el derecho al sufragio comprende también a las personas sentenciadas. En todos los casos se trata de modalidad de voto presencial, es decir, implica el establecimiento de mesas de votación dentro de los centros penitenciarios, lo que necesariamente implica la existencia de acuerdos y mecanismos de colaboración con las autoridades competentes, tanto para fines de organización y logística del proceso como para ofrecer todas las condiciones y medidas de seguridad requeridas para su debido desarrollo.

\section{FACILIDADES PARA EJERCER EL DERECHO AL VOTO}

En esta sección, la atención se centra en los dispositivos para promover la inclusión de personas pertenecientes a distintos grupos o colectivos sociales que, sin padecer 0 enfrentar explícitamente alguna exclusión o impedimento de carácter legal para el disfrute de sus derechos políticos, sí tienen dificultades o enfrentan obstáculos para su debido o efectivo ejercicio. Entre los grupos que, en buena medida, se han concebido como principales destinatarios de los dispositivos y medidas de inclusión electoral alentadas o privilegiadas en los últimos años destacan el de las personas con alguna discapacidad ${ }^{6}$; el de las personas recluidas en centros hospitalarios, de salud o de cuidado; o incluso simplemente el de las personas que por razones de salud o de edad enfrentan dificultades para comparecer de manera personal en las mesas de votación que les corresponde.

\footnotetext{
5 El fallo de la Corte Suprema de Chile se puede consultar en el siguiente enlace: https://www.24horas.cl/incoming/article2291363.ece/BINARY/Fallo\%20voto\%20reos, y el del Tribunal Electoral de México en https://www.te.gob.mx/Informacion_juridiccional/sesion_publica /ejecutoria/sentencias/SUP-JDC-0352-2018.pdf

${ }^{6}$ El portal de la CEPAL incluye una amplia sección especializada sobre discapacidad e inclusión, en la que se pueden encontrar instrumentos jurídicos internacionales, empezando por la Convención Internacional sobre los Derechos de las Personas con Discapacidad, publicaciones especializadas e información general (https://biblioguias.cepal.org/c.php?g=159510\&p=1044403).
} 


\section{DERECHO EIECTORAL}

Para atender las necesidades de estos grupos, se han ideado e impulsado, en lo esencial, dos tipos de dispositivos o medidas de inclusión: 1. Los que trasladan o acercan las urnas a los sitios en que se encuentran recluidas esas personas, que puede ser su propio domicilio, dispositivos a los que para fines de este trabajo y para evitar confusiones denominaremos "urna móvil". 2. Los que ofrecen facilidades para que las personas que sí tienen posibilidades de concurrir al sitio de votación que les corresponde, puedan a pesar de alguna limitación o dificultad física ejercer su derecho al sufragio de la manera más accesible, cómoda, fácil o acorde con sus necesidades.

Es importante hacer notar que ambos dispositivos son compatibles, pero deben distinguirse de otra modalidad de votación que se ha empezado a adoptar en la región, la del voto anticipado. Este implica la instalación de mesas de votación antes de la jornada electoral ordinaria, para que las y los electores que saben de antemano que por determinada razón, sobre todo, aunque no exclusivamente, de carácter profesional o laboral, estarán alejados o no podrán concurrir a su sitio de votación el día de la jornada electoral, puedan hacerlo en sedes y mesas que se instalan y operan con antelación a la jornada. En esencia, todos estos dispositivos, operados sobre todo de manera combinada o sincronizada pueden tener un carácter altamente inclusivo y asequible prácticamente a cualquier persona con cualquier necesidad o requerimiento especial para poder emitir su voto.

\subsection{URNA MÓVIL}

La adopción de la urna móvil es una de las innovaciones más reciente y aún incipiente en la región, a la fecha solo ha sido introducida con algunas variantes en cinco países: Ecuador, Paraguay, República Dominicana, Honduras y México, en ese orden. Por ahora tiene carácter extraordinario, puesto que atiende selectiva y exclusivamente a personas con problemas de discapacidad, salud o movilidad que cumplen con requisitos muy puntuales. La Tabla 1 muestra algunas características básicas de los cinco países con registro positivo. 


\section{DERECHOELECTORAL}

SEGUNDO SEMESTRE 2020 NÚMERO 30

ISSN: 1659-2069

Tabla 1

Países con dispositivos de urna móvil
País
Año
inicio
Principales características

Inició como piloto y en 2017 se amplió a nivel nacional. Comprende exclusivamente a las personas con discapacidad física severa igual o mayor al $75 \%$ y que tengan al menos 65 años de edad. Las

Ecuador $\quad 2013$ personas susceptibles de acceder al programa se identifican a partir de la información que provee el Ministerio de Salud Pública y que la autoridad electoral se encarga de verificar y validar. El dispositivo se aplica dos días antes de la jornada electoral ordinaria.

Es de alcance regional, pero se ha ido ampliando. Comprende a personas con discapacidad física severa (sin imponer umbral), a las que presenten disfuncionalidad motora severa o a las que por Paraguay 2015 motivos graves de salud no puedan comparecer en un sitio de votación. Los requisitos están sujetos a inspección o validación del organismo electoral. No se impone límite de edad para acceder al programa, pero sí al universo de posibles beneficiarios: no puede ser superior al 0,05\% del total de electores habilitados.

Proyecto inicial limitado a un pequeño universo de 100 personas, República $\quad 2016$ seleccionadas aleatoriamente de una base de datos que integre a Dominicana 2016 todas aquellas con una condición de discapacidad severa que les imposibilite desplazarse a un centro de votación.

Proyecto piloto en dos ciudades que comprendió a menos de 20 Honduras 2017 personas con reducción de movilidad superior al $60 \%$, en estado lúcido y mayores de 65 años.

Proyecto piloto que comprendió la instalación de una urna dentro de un hospital de cada una de las 32 entidades federativas para facilitar

México 2018 la emisión del voto a personas hospitalizadas, familiares o personas a su cuidado y personal de guardia durante la jornada electoral. Solo en el hospital de la capital del país la urna tuvo también función móvil para trasladarse a habitación de pacientes.

Ecuador es el país pionero en la región y los cuatro países que han replicado este tipo de dispositivo lo han tomado como principal referente $y$, también, han optado de inicio por un enfoque gradual y selectivo, que ha partido de proyectos piloto de pequeña escala. Si bien por ahora es una modalidad que, en casi todos los casos, solo es accesible para personas con discapacidad que cumplen requisitos muy rigurosos y selectivos, en general suele formar parte de un paquete más amplio e integral de medidas que buscan promover la inclusión y participación política de mayores segmentos de electores con requerimientos especiales. 


\section{DERECHO ELECTORAL}

\subsection{VOTO ACCESIBLE, ASISTIDO O PREFERENTE EN MESA}

En este terreno son notables los progresos en la región. Todos los países cuentan con programas o medidas específicas orientadas a posibilitar o facilitar el voto en mesa, concebidos sobre todo para electoras y electores con discapacidad, pero que con frecuencia benefician también a otros segmentos del electorado. En la mayoría de los casos esos programas o medidas están consagrados en el marco legal, pero también hay algunos que derivan de acuerdos o iniciativas impulsados por el organismo electoral, en ocasiones en coordinación o con la colaboración de instituciones o agrupaciones relacionadas con las personas beneficiarias.

El grueso de los dispositivos que forman parte de esos programas o medidas suelen instrumentarse durante la jornada electoral. Sin embargo, en algunos países existen facilidades que se ponen en operación con anterioridad y en preparación de los apoyos previstos para la jornada electoral. En Costa Rica o República Dominicana, por ejemplo, se llevan a cabo operativos para fines de registro electoral a domicilio, que comprenden fundamentalmente a personas con discapacidad. En Bolivia se instrumentan también operativos de este tipo, aunque enfocados en centros de reunión, atención o cuidado de esas personas. En otros como Colombia, Perú o Venezuela, se adoptan medidas que durante el proceso de integración o actualización de los padrones de electores permitan identificar a las y los electores con alguna discapacidad para prever los apoyos que se les puedan brindar durante la jornada comicial al momento de presentarse en el recinto electoral.

Centrando la atención en la jornada electoral, un esfuerzo que se ha venido desplegando sistemáticamente a lo largo de los últimos años en la región tiene que ver con la adopción de medidas para facilitar el ingreso a los recintos de votación por parte de personas con necesidades especiales. Entre las medidas más usuales figuran, de ser el caso, las de colocar rampas o eliminar barreras físicas que dificulten u obstruyan el acceso a los recintos; las de procurar ubicar las mesas de votación en la planta baja de los recintos seleccionados o, por lo menos, ubicar en la planta baja las mesas en que deban votar las y los electores con alguna discapacidad.

Antes de cerrar este apartado, es necesario comentar que el grueso de los dispositivos, medidas o acciones adoptadas en los países de América Latina para promover la inclusión electoral de las personas con discapacidad tiene 


\section{DERECHO EIECTORAL}

su centro de gravedad o hilo conductor en discapacidades de carácter físico o psicomotriz en sus distintas variantes. Y eso tiene mucho de positivo. Sin embargo, dentro de la gama de discapacidades que reconocen tanto instrumentos jurídicos como instituciones y organismos especializados figuran unas que, quizá por la complejidad de ser atendidos debidamente, no sólo tienden a ser eludidas en debates e iniciativas de inclusión, sino que incluso siguen padeciendo restricciones de carácter legal, al menos cuando se trata de la titularidad y el ejercicio de los derechos políticos: las de carácter intelectual o psicosocial ${ }^{7}$.

En efecto, si bien teóricamente muchos de los dispositivos y mecanismos de inclusión y accesibilidad electoral para las personas con discapacidad puestos en práctica en la región ${ }^{8}$ pueden comprender a quienes padecen discapacidades intelectuales o psicosociales, lo cierto es que no hay mayor evidencia de que los guíe alguna orientación o intención expresa en ese sentido. Lo anterior, sin obviar que en algunos países siguen pesando restricciones de carácter legal para el disfrute y ejercicio de los derechos políticos por parte de esas personas.

\subsection{COMUNIDAD LGTBI: PERSONAS TRANSGÉNERO}

Una de las manifestaciones más elocuentes del impacto que han tenido los esfuerzos e iniciativas de la comunidad internacional para promover y proteger al máximo los derechos humanos de todas las personas en un marco de pleno respeto a la pluralidad y la diversidad, lo constituye sin duda la eclosión de movimientos y comunidades que reivindican diversas identidades de género y preferencias sexuales, a las cuales suele agruparse bajo las siglas LGTBI.

En la mayoría de las sociedades contemporáneas, las principales reivindicaciones y exigencias de estos movimientos y comunidades tienen que ver con la garantía y el respeto de derechos humanos básicos (sobre todo civiles y sociales). Si bien los asuntos relacionados con sus derechos político-electorales aún no ocupan un lugar prioritario de su agenda, sí se

\footnotetext{
${ }^{7}$ En el grueso de los países de la región, como en el de otras partes del mundo, aún pesan fuertes limitantes legales para que las personas con discapacidad intelectual, psicosocial o cognitiva puedan asumir la titularidad y ejercer sus derechos políticos, empezando por el voto activo. España es uno de los pocos países que ha eliminado, mediante una reforma electoral aprobada a finales de 2018, todas las restricciones en este sentido. 8 Tal es el caso del TSE de Costa Rica sobre la decisión de instalar juntas receptoras de votos en hogares de ancianos (Resolución 958-E-2006) y centros médicos siquiátricos (Resolución 1224-E1-2014).
} 


\section{DERECHO EIECTORAL}

pueden identificar algunos nudos problemáticos en los que ya se han demandado y se han realizado algunas intervenciones concretas. Por ahora, los más visibles tienen que ver con las personas trans ${ }^{9}$ (comprende trasvestis, transgénero y transexuales), porque en esta comunidad en especial, es manifiesta la falta de correspondencia u oposición (bajo el parámetro binario convencional mujer-hombre), entre el nombre y la identidad de género que reivindican y la que se les asignó de origen en los registros de carácter civil y en los consecuentes documentos de identificación.

Esa falta de correspondencia no sólo puede producir actos discriminatorios o vejatorios, sino, además, inhibir, complicar o incluso hacer nugatorio el ejercicio de sus derechos al sufragio activo y pasivo. Por ello, la demanda de que se les reconozca jurídicamente su identidad de género (nombre y sexo 0 , incluso, una nueva identidad acorde) tiene importantes implicaciones en varios ámbitos de la vida social, incluyendo el políticoelectoral.

Por su naturaleza, la posibilidad de introducir cambios en los registros y documentos de identificación oficiales acordes con la identidad reivindicada por las personas trans requiere adecuaciones al marco jurídico sea a través de reformas legislativas, de sentencias judiciales o de decretos ejecutivos. Con frecuencia se trata de procesos y gestiones que implican un arduo empeño, en ocasiones escarpado, que no solo tienen que hacer frente a las resistencias que derivan de concepciones y prejuicios de fuerte raigambre cultural y religiosa, sino, demás, a la remoción de cuestionables requisitos que se han llegado a imponer en el marco legal como condición de procedencia para realizar los cambios exigidos.

En este sentido, aunque el panorama regional es heterogéneo, es perceptible una tendencia positiva en pro de garantizar o facilitar la posibilidad de que las personas trans puedan llevar a cabo las gestiones necesarias para una adecuación legal en su identidad de género, con lo cual zanjar de manera significativa la reivindicación y ejercicio de sus derechos políticos a partir de sus nuevos rasgos identitarios o, por lo menos, salvar algunos obstáculos y contar con facilidades administrativas para ello.

\footnotetext{
${ }^{9}$ Entre los muchos portales en donde se puede encontrar información básica sobre la situación y derechos de la comunidad LGTBI, se puede mencionar el de Amnistía Internacional (https://www.amnesty.org/es/whatwe-do/discrimination/lgbt-rights/.
} 


\section{DERECHO EIECTORAL}

\section{Tabla 2}

Países que permiten cambios de identidad a las personas trans o facilitan el ejercicio de sus derechos

País y año de

adopción o inicio

Argentina

(2012)

\begin{tabular}{|c|c|c|}
\hline (2012) & (Ley n. $\left.{ }^{\circ} 26.743\right)$ & Fotografía \\
\hline $\begin{array}{l}\text { Bolivia } \\
(2016)\end{array}$ & $\begin{array}{l}\text { Ley de Identidad de Género } \\
\text { (Ley } \mathrm{n} .{ }^{\circ} 807 \text { ) }\end{array}$ & $\begin{array}{l}\text { Nombre } \\
\text { Sexo } \\
\text { Fotografía }\end{array}$ \\
\hline $\begin{array}{c}\text { Brasil } \\
(2018)\end{array}$ & Sentencia del Supremo Tribunal Federal & Nombre \\
\hline $\begin{array}{l}\text { Chile } \\
(2018)\end{array}$ & $\begin{array}{l}\text { Ley de Identidad de Género } \\
\text { (Ley } .^{\circ} 21.120 \text { ) }\end{array}$ & $\begin{array}{l}\text { Nombre } \\
\text { Género }\end{array}$ \\
\hline $\begin{array}{l}\text { Colombia } \\
(2018)\end{array}$ & $\begin{array}{l}\text { Decreto } 1227 \text { aprobado por los ministerios del } \\
\text { Interior y de Justicia }\end{array}$ & $\begin{array}{l}\text { Nombre } \\
\text { Sexo }\end{array}$ \\
\hline $\begin{array}{l}\text { Costa Rica } \\
(2018)\end{array}$ & $\begin{array}{l}\text { Decreto 7-2018 del Tribunal Supremo de } \\
\text { Elecciones }\end{array}$ & $\begin{array}{l}\text { Nombre } \\
\text { (se suprime sexo) }\end{array}$ \\
\hline $\begin{array}{l}\text { Ecuador } \\
\text { 2016) }\end{array}$ & $\begin{array}{l}\text { Ley Orgánica de Gestión de la Identidad y Datos } \\
\text { Civiles }\end{array}$ & $\begin{array}{l}\text { Nombre } \\
\text { Género }\end{array}$ \\
\hline $\begin{array}{l}\text { México } \\
\text { (2018) }\end{array}$ & $\begin{array}{l}\text { Fallo de la Suprema Corte de Justicia y } \\
\text { Protocolo emitido por la autoridad electoral }\end{array}$ & $\begin{array}{l}\text { Protocolo para facilitar emisión } \\
\text { del voto }\end{array}$ \\
\hline $\begin{array}{l}\text { Perú } \\
\text { (2016) }\end{array}$ & $\begin{array}{l}\text { Sentencia del Tribunal Constitucional } \\
\left.\text { (n. }{ }^{\circ} 06040-2015-P A / T C\right)\end{array}$ & $\begin{array}{l}\text { Nombre } \\
\text { Sexo }\end{array}$ \\
\hline $\begin{array}{c}\text { Uruguay } \\
(2009 \text { y } 2018)\end{array}$ & $\begin{array}{l}\text { Ley de Regulación del Derecho a la Identidad de } \\
\text { Género y Ley Integral para Personas Trans }\end{array}$ & $\begin{array}{l}\text { Nombre } \\
\text { Sexo }\end{array}$ \\
\hline
\end{tabular}

Cambios en documento de

Instrumento legal identidad

Nombre

Sexo

tografia

Sexo

Como se muestra en la Tabla 2, ya en más de la mitad de los países, existen instrumentos jurídicos o mecanismos que reconocen el derecho o permiten realizar cambios de nombre $y$, en la mayoría de ellos, también de género, por simple vía administrativa, es decir, sin que tengan que mediar intervenciones judiciales. En cinco de esos países (Argentina, Bolivia, Chile, Ecuador y Uruguay), se trata de derechos reconocidos por leyes nacionales de identidad. En tres (Brasil, Costa Rica y Perú) su soporte son resoluciones judiciales de tribunales superiores. En Colombia lo es un decreto presidencial. En México hay tanto resolución judicial como normas 


\section{DERECHO EIECTORAL}

favorables en la legislación de algunos de sus estados, pero para fines político-electorales, la autoridad electoral ha jugado un papel clave ${ }^{10}$.

\section{MeCANISMOS Y GaRANTÍAS DE REPRESENTACIÓN POLÍtiCA}

Esta sección se enfoca en tres grupos en los que el concepto de inclusión político-electoral alcanza un estadio superior, el de la existencia de mecanismos para promover e, incluso, para garantizar su representación política, es decir, el acceso a cargos de representación popular. Los grupos considerados son los pueblos originarios, comunidades indígenas u otros grupos étnicos; la diáspora y las mujeres. Con esos mecanismos y garantías se puede tratar de alcanzar objetivos políticos muy diversos: desde saldar viejas deudas históricas hasta resolver problemas de cohesión, legitimidad o gobernabilidad, pasando, por supuesto, por elementales imperativos de justicia o equidad social.

El hecho de que, con estos tres grupos en lo particular como con algunos otros que en otros contextos pueden resultar necesarios o pertinentes, se privilegien mecanismos de inclusión y representación política, no significa necesariamente que no existan ni mucho menos que se hayan superado apropiadamente otras exigencias o desafíos de inclusión electoral como los planteados en las secciones precedentes. Al contrario, solo implica, si así se puede sintetizar, que sus exigencias de inclusión son de tal densidad y magnitud que tienen y demandan una atención y respuesta más integrada, omnicomprensiva.

\subsection{Pueblos ORIginarios, COMUNIDADES INDÍgenAS U OTROS GRUPOS ÉTNICOS}

No deja de ser paradójico que en el grueso de las sociedades americanas, los pueblos originarios y las comunidades indígenas (pero también en lo consecuente, otros grupos étnicos, notablemente los afrodescendientes) no solo sigan padeciendo condiciones de exclusión y marginación, sino que además, y a diferencia de lo que ocurrió en casi todas las otras regiones y latitudes, los procesos de independencia no les hayan reportado ni el

\footnotetext{
${ }^{10}$ El documento que refiere con detalle el Protocolo adoptado por el Instituto Nacional Electoral de México para garantizar el voto de las personas trans en 2018 se puede consultar en el siguiente enlace: https://www.ine.mx/wp-content/uploads/2018/06/DECEyEC-Protocolo-Trans.pdf
} 


\section{DERECHO EIECTORAL}

respeto de sus tradiciones, ni la restitución de sus derechos, ni estatutos formales de igualdad, ni mucho menos roles políticos dominantes.

Las condiciones de exclusión, discriminación y marginación que ancestralmente han padecido los pueblos originarios y comunidades indígenas solo han empezado a ser enfrentadas de manera relativamente reciente. El Convenio sobre Pueblos Indígenas y Tribales adoptado por la Organización Internacional del Trabajo (OIT) en 1989, que consagra su derecho a la libre autodeterminación, pero sobre todo los compromisos derivados de la Declaración de la ONU sobre Derechos Indígenas de 2007 marcan un importante punto de inflexión en esa dirección. Sobre esa base, han detonado o se han acentuado en América Latina una gran cantidad de reformas constitucionales y legales, de iniciativas y programas orientados a reconocer y garantizar derechos en varias dimensiones, incluyendo la de la inclusión y la participación política.

Por el cuadro de condiciones que han padecido y se busca superar, ha sido necesario que los esfuerzos de inclusión política de los pueblos originarios comprendan un muy amplio abanico de dispositivos y acciones. Muchos de estos guardan relación o pueden quedar comprendidos dentro de los que se han diseñado y operado para atender las necesidades de otros grupos o comunidades que se examinan en este artículo, pero algunos otros solo son discernibles y resultan pertinentes para las y los integrantes de los pueblos originarios.

En este sentido, vale la pena destacar dos modalidades en particular. La primera remite a tradiciones comunitarias de los pueblos originarios que articulan los principios de participación electoral y representación política y se expresan en el reconocimiento de sus propios métodos para la selección y renovación de sus autoridades, invariablemente de carácter local o comunitario, o bien para que sean sus representantes en asambleas legislativas. Los de Bolivia y México $^{11}$ son casos especialmente representativos del reconocimiento, a nivel constitucional, de un conjunto de derechos a los pueblos originarios, entre los que figuran el del respeto a sus métodos o mecanismos tradicionales (comunitarios) para elegir a sus

\footnotetext{
${ }^{11}$ En el siguiente enlace se puede encontrar una panorámica sobre el derecho electoral comparado de las comunidades indígenas en América Latina, que corresponde a una ponencia presentada en un Congreso Internacional sobre Usos y Costumbres Indígenas celebrado en 2008: http://historico.juridicas.unam.mx/publica/librev/rev/qdiuris/cont/7/cnt/cnt4.pdfhttps://www.te.gob.mx/sites /default/files/sr_14_usos.pdf
} 


\section{DERECHO EIECTORAL}

autoridades a nivel local e, incluso, en el caso de Bolivia, a las personas que los pueden llegar a representar en asambleas departamentales.

La segunda se refiere a mecanismos convencionales de participación en la competencia por acceder a cargos de elección popular. Bajo esta segunda modalidad figuran, por una parte, las garantías o facilidades que tienen los pueblos originarios para conformar sus propias fuerzas o agrupaciones políticas y contender a través de ellas por cargos electivos. En la mayoría de los países de la región existen y la legislación admite, de manera expresa o tácita, la posibilidad de que contiendan en procesos electorales a nivel nacional o subnacional formaciones políticas con clara filiación u orientación adscrita a causas o intereses de pueblos o comunidades originarias o relacionadas con esas causas o intereses. Por los principios consagrados en sus novedosos textos constitucionales, Bolivia y Ecuador son ejemplos representativos de esta dinámica, pero también los hay en otros países de la región como Guatemala, Nicaragua o Venezuela.

Por último, la Tabla 3 refleja los aspectos básicos de los cuatro países en los que representantes de los pueblos originarios tienen garantizada su representación en las asambleas legislativas de carácter nacional.

Tabla 3

Escaños reservados para representantes de pueblos originarios

\begin{tabular}{|c|c|c|}
\hline País & $\begin{array}{l}\text { Número de } \\
\text { escaños }\end{array}$ & Características \\
\hline Bolivia & $\begin{array}{l}7 \text { de } 130 \text { de la } \\
\text { Asamblea Nacional }\end{array}$ & $\begin{array}{l}\text { Son circunscripciones especiales que se configuran en } \\
\text { función de la distribución y peso territorial de los pueblos } \\
\text { y comunidades indígenas que se revisan y ajustan } \\
\text { periódicamente. }\end{array}$ \\
\hline \multirow{2}{*}{ Colombia } & $\begin{array}{l}1 \text { de } 166 \text { de la } \\
\text { Cámara } \\
\text { Representantes }\end{array}$ & $\begin{array}{l}\text { Forma parte de una circunscripción nacional especial que } \\
\text { comprende cuatro escaños. }\end{array}$ \\
\hline & $\begin{array}{l}2 \text { adicionales a los } \\
100 \text { del Senado }\end{array}$ & $\begin{array}{l}\text { Forma parte de una circunscripción especial nacional en la } \\
\text { que solo se eligen los dos escaños de comunidades } \\
\text { indígenas. }\end{array}$ \\
\hline México & $\begin{array}{l}13 \text { de } 500 \text { de la } \\
\text { Cámara } \\
\text { Diputados }\end{array}$ & $\begin{array}{l}\text { Corresponden a } 13 \text { de los } 300 \text { distritos de mayoría } \\
\text { relativa en los que haya mayoría de población indígena. }\end{array}$ \\
\hline Venezuela & $\begin{array}{l}3 \text { de } 167 \text { de la } \\
\text { Asamblea Nacional }\end{array}$ & $\begin{array}{l}\text { Se conforman tres circunscripciones territoriales en las } \\
\text { que se agrupan las zonas con mayor población indígena. }\end{array}$ \\
\hline
\end{tabular}




\section{DERECHO EIECTORAL}

Resulta obligado mencionar el caso de Colombia, pues es el único país de la región que garantiza la representación política de las personas afrodescendientes, ya que dos de los cuatro escaños que comprende la circunscripción especial les corresponden precisamente a representantes de esa comunidad. La situación de estas comunidades no es menos compleja, en términos de marginación y discriminación, que la de los pueblos originarios, y los esfuerzos por visibilizarlos y atenderlos son muy incipientes, a pesar de que representan más de $20 \%$ de la población total de la región ${ }^{12}$.

\subsection{VOTO EN EL EXTRANJERO Y DERECHOS POLÍtICOS DE LA DIÁSPORA}

En el último cuarto de siglo, el número de países de América Latina que reconocen y han adoptado las regulaciones legales necesarias para permitir el ejercicio del derecho al voto fuera de sus fronteras ha pasado de tres a 16 (Tabla 4). Ese número representa una abrumadora mayoría de los 18 países considerados para este estudio (salvo Nicaragua y Uruguay), y convierte a la región en la que registra el mayor porcentaje de casos positivos en el mundo ${ }^{13}$.

Ese indicador es consecuente y refleja, en su muy particular ámbito de acción, la centralidad que se le ha concedido en el grueso de los países de la región a los esfuerzos orientados a arraigar y robustecer las normas, instituciones y procedimientos electorales como un elemento clave de los procesos de cambio y fortalecimiento democrático. Es cierto que el reconocimiento y la regulación del voto en el extranjero no se han perfilado como piedra angular de los procesos de reforma que se han producido en la región, pero, tarde o temprano, la lógica de algunos de sus objetivos o el peso de sus exigencias han logrado abrirse paso y generar los acuerdos necesarios para quedar plasmados en la ley.

\footnotetext{
12 Sobre la situación y los derechos de las personas afrodescendientes en América Latina, se sugiere consultar las siguientes publicaciones en línea de la CEPAL: https://www.cepal.org/es/publicaciones/7227afrodescendientes-america-latina-caribe-reconocimiento-estadistico-la-realizacion y https://www.cepal.org/es /publicaciones/42654-situacion-personas-afrodescendientes-america-latina-desafios-politicas-la

${ }^{13}$ Para un examen detallado, aunque un poco desactualizado, pues corresponde a una edición de 2016, de las regulaciones sobre el voto en extranjero en América Latina se puede consultar la siguiente publicación: https://www.undp.org/content/dam/undp/library/Democratic\%20Governance/Electoral\%20Systems\%20and \%20Processes/Voto\%20en\%20el\%20Extranjero\%20en\%2018\%20Pa\%C3\%ADses\%20de\%20Am\%C3\%A9ric a\%20Latina.pdf

Para información más actualizada se puede consultar la base de datos global sobre el tema de IDEA Internacional: https://www.idea.int/data-tools/data/voting-abroad
} 


\section{DERECHO EIECTORAL}

\section{Carlos Marino Navarro Fierro}

Tabla 4

Países con voto en el extranjero

País/año inicio

Argentina

(1993)

Bolivia

(2009)

Brasil

(1989)

Chile

(2017)

Colombia

(1962)

Costa Rica

(2014)

El Salvador

(2012)

Ecuador
(2002)

Guatemala

(2019)

\begin{tabular}{lll}
\hline $\begin{array}{l}\text { Honduras } \\
\mathbf{( 2 0 0 1 )}\end{array}$ & Presidenciales & $\begin{array}{l}\text { Presencial (sólo en Estados } \\
\text { Unidos) }\end{array}$ \\
\hline $\begin{array}{l}\text { México } \\
\mathbf{( 2 0 0 6 )}\end{array}$ & $\begin{array}{l}\text { Presidenciales } \\
\text { Legislativas (solo Senado) } \\
\text { Locales }\end{array}$ & $\begin{array}{l}\text { Postal } \\
\text { Internet (2021) }\end{array}$ \\
\hline $\begin{array}{l}\text { Panamá } \\
(\mathbf{2 0 0 6 )}\end{array}$ & Presidenciales & $\begin{array}{l}\text { Postal } \\
\text { Internet }\end{array}$ \\
\hline $\begin{array}{l}\text { Paraguay } \\
(\mathbf{2 0 1 3 )}\end{array}$ & $\begin{array}{l}\text { Presidenciales } \\
\text { Legislativas (solo Senado) }\end{array}$ & Presencial \\
\hline $\begin{array}{l}\text { Perú } \\
\mathbf{( 1 9 8 0 )}\end{array}$ & $\begin{array}{l}\text { Presidenciales } \\
\text { Legislativas }\end{array}$ & Presencial \\
\hline $\begin{array}{l}\text { R Dominicana } \\
(\mathbf{2 0 0 4 )}\end{array}$ & $\begin{array}{l}\text { Presidenciales } \\
\text { Legislativas (ambas Cámaras) }\end{array}$ & Presencial \\
\hline $\begin{array}{l}\text { Venezuela } \\
(\mathbf{1 9 9 8 )}\end{array}$ & $\begin{array}{l}\text { Presidenciales } \\
\text { Consultas populares }\end{array}$ & Presencial (urna electrónica) \\
\hline
\end{tabular}

\section{Tipo de elecciones a las que aplica Modalidad de emisión del voto}

Presidenciales

Legislativas (ambas Cámaras) Presencial

Presidenciales Presencial

Consultas populares

Presencial (urna electrónica)

Presencial

Consultas populares

Presencial

Legislativas (ambas Cámaras)

Consultas populares

Presencial

Presidenciales

Consultas populares

Postal

Presidenciales

Locales (2021)

Presencial

Legislativas

Presencial

Presidenciales

Presencial

Presencial (sólo en Estados

Postal

(2021)

Legislativas (solo Senado)

Postal

\section{Presidenciales}

Legislativas (solo Senado)

Legislativas

Consultas populares

Presencial

Presidenciales

Presencial (urna electrónica)

La tendencia progresiva en el reconocimiento de derechos políticos de la diáspora alcanza, hoy en día, una de sus expresiones más acabadas en la 


\section{DERECHO EIECTORAL}

adopción de dispositivos legales que garantizan su representación parlamentaria por la vía de escaños reservados. Si bien hasta ahora son únicamente tres los países (Colombia, Ecuador y República Dominicana) cuya legislación reconoce y garantiza este derecho para efectos de la integración de su asamblea de representantes populares a nivel nacional, es pertinente destacar que se trata de una reivindicación que está siendo enarbolada por la diáspora de muchos otros países de la región, por lo que es posible que en un futuro próximo se expanda el número de registros de este tipo.

La Tabla 5 refiere algunas características básicas de los dispositivos previstos para garantizar la representación política de la diáspora en estos tres países.

Tabla 5

Escaños para la diáspora

País

Colombia

República

Dominicana
Número de escaños

Dos de 166 de la Cámara Baja

6 de 137 de la Asamblea Nacional

7 de 190 de la Cámara Baja
Características básicas

Una sola circunscripción para todo el mundo.

Tres circunscripciones con dos escaños cada una: una la forman Estados Unidos y Canadá, otra América Latina, el Caribe y África, y la última Asia y Oceanía.

Tres circunscripciones que solo comprenden nueve países: la primera corresponde a Canadá y el norte de Estados Unidos con tres escaños; la segunda comprende el sur de Estados Unidos, Puerto Rico, Panamá y Venezuela, con dos escaños y la última cuatro países de Europa (España, Italia, Países Bajos y Suiza), con dos escaños.

\subsection{MuJERES: CUOTAS Y EQUIDAD DE GÉNERO}

En términos de la reivindicación, reconocimiento y ejercicio efectivo de los derechos político-electorales, es probable que ningún trayecto haya resultado más largo, complejo y sinuoso que el de las mujeres. También aquí estamos frente a una monumental deuda histórica con hondas y profundas raíces de opresión e injusticia que, por supuesto, trascienden por 


\section{DERECHO ELECTORAL}

completo el estricto plano político-electoral y que solo muy recientemente se han empezado a entender y tratar de afrontar a cabalidad.

Es claro que, en el caso de las mujeres, las condiciones de opresión e injusticia por lo general se agravan o acentúan severamente si, además, se consideran otros vectores sociales como su pertenencia a grupos vulnerables, marginados o discriminados como, en el contexto de América Latina, los pueblos originarios o afrodescendientes, o más en general, minorías étnicas o religiosas.

En todo caso y reconociendo esas especificidades, se puede postular, en un plano más general y formal, que las exigencias y expectativas mínimas de inclusión política de las mujeres están garantizadas y suelen ser atendidas, sobre todo en lo que respecta al reconocimiento y facilidades para el ejercicio del derecho al sufragio. De ahí que la atención en este artículo se centre en los dispositivos legales y acciones tendientes a privilegiar su representación política $y$, como obligado precedente, las que promueven o facilitan su derecho a postularse para cargos de elección popular. En este sentido, es importante hacer notar que la trayectoria seguida para promover su participación y representación política ha estado basada, en buena medida, en experiencias de ensayo y error. En efecto, quizá el periplo para asegurar la participación y la representación política no ha sido tan largo, en una dimensión estrictamente temporal, como el del reconocimiento del derecho al voto, pero no ha sido, ni sigue siendo, menos accidentado.

Ese complicado periplo inició con el advenimiento de acciones afirmativas en su más frágil acepción: las cuotas voluntarias. Ante pruebas manifiestas de falta de interés o voluntad política por cumplir el cometido planeado, al no mediar ni obligación ni sanción alguna, la legislación escaló al nivel siguiente: dotar a las disposiciones de fuerza vinculante; imponer a los contendientes la obligación de incluir en sus listas de candidaturas un porcentaje mínimo de mujeres. Un problema común con este tipo de disposiciones ha sido, y en algunos casos lo sigue siendo, que al no fijar parámetros para su aplicación, propicia la aparición de maniobras que terminaban por anular sus intenciones: se cumplía la letra, pero no su objetivo. Se incluía a mujeres en las listas de candidaturas, pero en demarcaciones electorales 0 en posiciones dentro de las listas que dificultaban, cuando no hacían casi imposible, su acceso a cargos electivos. 


\section{DERECHO EIECTORAL}

Frente a este escenario, se empiezan a concebir e impulsar nuevas iniciativas de carácter vinculante que buscan, por un lado, colocar las candidaturas de mujeres en posiciones dentro de las listas que efectivamente les concedan oportunidades de obtener escaños $y$, por ende, representación política y, por el otro, proveerles recursos y herramientas que les permitan contender en condiciones menos desventajosas. Para cumplir con el primer cometido, las cuotas de género ya no son sólo vinculantes, sino que ahora incluyen parámetros de exigencia para que su posición en las listas no quede al libre albedrío o la buena voluntad de las dirigencias partidistas.

El desarrollo más reciente dentro de los dispositivos legales y las líneas de acción encaminadas a promover la participación y el liderazgo político de las mujeres tiene como referente y paradigma la noción, las políticas y garantías de paridad de género (Tabla 6). Noción estrechamente asociada a la de la igualdad entre los sexos, se entiende como una participación equilibrada entre mujeres y hombres en las posiciones y procesos de toma de decisión en todas las esferas de la vida social ${ }^{14}$.

En el plano estrictamente político-electoral, ese concepto se ha traducido en disposiciones legales que apuntan a equilibrar o igualar al máximo posible no solo las oportunidades reales de contender por cargos de elección popular, sino, además, la integración efectiva de las instancias de representación política, en especial las de carácter colegiado (asambleas legislativas y concejos en los distintos niveles de gobierno).

La línea de progresión que se ha bosquejado en cuanto a la adopción de dispositivos legales para promover la participación y representación política de las mujeres no ha seguido ni sigue necesariamente una lógica secuencial u homogénea en las distintas jurisdicciones nacionales. En algunos casos, su valoración o adopción ha tenido que hacer frente y entrar en disputa con otras exigencias de cambio o fortalecimiento democrático como, por ejemplo, las cuotas versus la selección de candidaturas a través de elecciones internas o el desbloqueo de las listas para brindarle mayores libertades al electorado (voto preferencial).

\footnotetext{
${ }^{14}$ Sobre el principio de paridad y su aplicación en algunos países de América Latina, se recomienda el texto "La Apuesta por la Paridad: Democratizando el Sistema Político de América Latina" (http://www.oas.org/es/CIM/docs/ApuestaPorLaParidad-Final-Web.pdf).

IDEA Internacional también tiene una base de datos global sobre cuotas de género en la que se puede consultar información más detallada por país (https://www.idea.int/data-tools/data/gender-quotas).
} 


\section{DERECHO EIECTORAL}

Si bien su tratamiento escapa a los alcances de este estudio, no puede dejar de mencionarse la muy reciente visibilidad y notoriedad que ha adquirido el muy grave problema de la violencia de género, el que por supuesto tiene expresiones y comporta serias implicaciones en el terreno de la participación política de las mujeres. De ahí que resulte totalmente consecuente que, sobre todo en el marco de procesos electorales, hayan surgido iniciativas tanto de autoridades como de colectivos para hacer frente a este problema.

Tabla 6

Medidas afirmativas de género

\begin{tabular}{|c|c|c|}
\hline País & $\begin{array}{l}\text { Tipo de acción } \\
\text { afirmativaestablecida } \\
\text { legalmente }\end{array}$ & Observaciones \\
\hline Argentina & Paridad & $\begin{array}{l}\text { Comprende las listas de candidaturas al } \\
\text { Congreso nacional bajo el principio de } \\
\text { secuencia y alternabilidad. }\end{array}$ \\
\hline Bolivia & Paridad & $\begin{array}{l}\text { Comprende tanto las postulaciones a cargos } \\
\text { de mayoría como las listas de representación } \\
\text { proporcional en todos los niveles de } \\
\text { gobierno. }\end{array}$ \\
\hline Brasil & Cuota de $30 \%$ & $\begin{array}{l}\text { Solo comprende las listas para la Cámara } \\
\text { Baja, no el Senado. }\end{array}$ \\
\hline Chile & Cuota de $40 \%$ & Comprende las dos Cámaras del Congreso. \\
\hline Colombia & Cuota de $30 \%$ & Comprende las dos Cámaras del Congreso. \\
\hline Costa Rica & Paridad & $\begin{array}{l}\text { Comprende las listas de representación } \\
\text { proporcional para órganos colegiados de } \\
\text { todos los niveles de gobierno bajo los } \\
\text { criterios de secuencia y alternabilidad. }\end{array}$ \\
\hline El Salvador & Cuota de $30 \%$ & $\begin{array}{l}\text { Comprende las listas para la Asamblea } \\
\text { Nacional. }\end{array}$ \\
\hline Ecuador & Paridad & $\begin{array}{l}\text { Comprende las listas de representación } \\
\text { proporcional para órganos colegiados de } \\
\text { todos los niveles de gobierno bajo los } \\
\text { criterios de secuencia y alternabilidad, así } \\
\text { como las fórmulas de prefectura de distinto } \\
\text { género para ejecutivos locales elegidos por } \\
\text { mayoría. }\end{array}$ \\
\hline Guatemala & Ninguna & \\
\hline Honduras & Paridad & $\begin{array}{l}\text { Comprende todas las candidaturas a cargos } \\
\text { de elección popular. }\end{array}$ \\
\hline México & Paridad & $\begin{array}{l}\text { Comprende tanto las candidaturas de } \\
\text { mayoría como las de representación } \\
\text { proporcional para integrar el Congreso de la } \\
\text { Unión. }\end{array}$ \\
\hline
\end{tabular}




\section{DERECHO EIECTORAL}

\begin{tabular}{|c|c|c|}
\hline Nicaragua & Paridad & $\begin{array}{l}\text { Comprende las listas de representación } \\
\text { proporcional para órganos colegiados de } \\
\text { todos los niveles de gobierno bajo los } \\
\text { criterios de secuencia y alternabilidad. }\end{array}$ \\
\hline Panamá & Paridad & $\begin{array}{l}\text { Se aplica solo a las elecciones internas o } \\
\text { primarias de los partidos para elegir } \\
\text { candidaturas. }\end{array}$ \\
\hline Paraguay & Cuota de $20 \%$ & $\begin{array}{l}\text { Se aplica solo a las elecciones internas o } \\
\text { primarias de los partidos para elegir } \\
\text { candidaturas. }\end{array}$ \\
\hline Perú & Cuota de $30 \%$ & Comprende las dos Cámaras del Congreso. \\
\hline R Dominicana & Cuota de $33 \%$ & $\begin{array}{l}\text { Solo comprende las listas para la Cámara } \\
\text { Baja, no el Senado. }\end{array}$ \\
\hline Uruguay & Ninguna & \\
\hline Venezuela & Paridad & $\begin{array}{l}\text { El criterio es flexible, pues lo fija la autoridad } \\
\text { para cada proceso electoral y admite rango } \\
\text { variable de hasta } 60 / 40 \% \text {. }\end{array}$ \\
\hline
\end{tabular}

\section{APUNTE final}

A no dudarlo, en las últimas dos o tres décadas se han concebido, fraguado y desplegado en el grueso de los países de América Latina, al igual que en los de otras regiones del mundo, diversas reformas, políticas, programas y esfuerzos orientados a fortalecer sus regímenes político-electorales en un sentido y con un carácter democrático. El cuadro de condiciones, en especial las socioeconómicas, y el clima general de opinión a los que han tenido que hacer frente o salir al paso no han sido, por mucho, los más propicios. Por el contrario, es un escenario plagado por igual de desigualdades e injusticias, de cuestionamientos y exigencias que cada vez desbordan con mayor frecuencia y facilidad los marcos y capacidad de acción estatal, aquellos empeños parecen nadar a contracorriente y alejarse de lograr sus cometidos fundamentales. Imperan tiempos de incertidumbre, confusión y desconfianza, atizados ahora y en el horizonte que en medio de esta niebla se vislumbra, por la pandemia del covid-19.

$Y$, sin embargo, en este pequeño estudio se ha tratado de mostrar que un componente central de los empeños de arraigo y fortalecimiento de normas, instituciones y prácticas democráticas en la región han sido los dispositivos y acciones orientados a superar las condiciones de exclusión, marginalización, discriminación o subrepresentación política y/o electoral que han padecido, o lo siguen haciendo, diversos grupos, comunidades y colectivos sociales. Se trata de empeños y avances nada desdeñables de 


\section{DERECHO EIECTORAL}

inclusión, participación y representación política que probablemente no han tenido ni el reconocimiento ni el impacto esperados.

Desde luego, aun en este pequeño y muy acotado terreno de juego, seguro subsisten carencias, limitaciones e insuficiencias. Siguen existiendo notables barreras legales para que las personas con discapacidades psicosociales puedan ejercer derechos básicos; contrariando el espíritu de la ley, a las personas encarceladas sin sentencia se les siguen vulnerando, en muchos países, esos mismos derechos; más allá de falsos prejuicios, las personas que viven a la intemperie o no tienen un domicilio convencional o fijo tienden a vivir, también, en el desamparo político-electoral. Aunque la juventud no constituye, en rigor, un signo identitario como el de otros grupos o colectivos considerados, porque se basa de un factor cronológico, temporal, común, generalizado, ineludible y transitorio, no dejan de ser perceptibles y lamentables sus muy bajos niveles de presencia en instancias de representación política para hacer frente a desafíos que demandan visiones y propuestas novedosas, ningún otro país de la región ha adoptado dispositivo legal alguno ni para promover la postulación de jóvenes a cargos electivos de carácter nacional ni para garantizar su representación en los congresos o asambleas nacionales. El repertorio de asignaturas pendientes y de nuevos desafíos da para más.

Con todo y por más paradas que deriven o se infieran del encuentro entre las tendencias y dinámicas planteadas, un argumento contra-fáctico resulta válido y pertinente. Sin estos granos de arena, el panorama podría resultar más sombrío, menos alentador, para miles, millones de personas que continúan creyendo que la convivencia social bajo principios y valores democráticos sigue significando el mejor de los mundos deseables, y aún posibles.

\section{REFERENCIAS BIBLIOGRÁFICAS}

Chile. Corte Suprema (2017). Sentencia Rol 87.743-2016 del dos de febrero.

Costa Rica. Tribunal Supremo de Elecciones (2006). Resolución 958-E-2006 de las siete horas con diez minutos del primero de marzo.

Costa Rica. Tribunal Supremo de Elecciones (2014). Resolución 1224-E1-2014 de diez horas con cincuenta minutos del primero de abril. 


\section{DERECHO EIECTORAL}

México. Instituto Nacional Electoral (2016). El Voto en el extranjero en 18 países de América Latina. México: INEC.

México. Instituto Nacional Electoral (2018). Protocolo para adoptar las medidas tendientes a garantizar a las personas trans el ejercicio del voto en igualdad de condiciones y sin discriminación en todos los tipos de elección y mecanismos de participación ciudadana. México: INE.

México. Tribunal Electoral del Poder Judicial de la Federación (2019). Sentencia SUP-JDC-352/2018 y acumulado del veinte de febrero.

Nava, S. (2008). Derecho indígena electoral comparado. Ponencia presentada en el marco del Primer congreso internacional sobre usos y costumbres Indígenas en Materia Electoral, 2-3 octubre.

Oficina Internacional del Trabajo (2014). Convenio número 169 de la OIT sobre Pueblos Indígenas y Tribales. Lima, Perú: Organización Internacional del Trabajo. Oficina Regional para América Latina y el Caribe.

Organización para la Seguridad y la Cooperación en Europa (2008). Manual sobre derechos humanos y libertades fundamentales sobre el personal de las fuerzas armadas. Varsovia, Polonia: OSCE. Recuperado de https://www.casede.org/index.php/biblioteca-casede-2-0/derechos-humanos/ 279-manual-sobre-derechos-humanos-y-libertades-fundamentales-delpersonal-de-las-fuerzas-armadas/file 